\title{
Investigating the capability of Smart City in Tehran
}

\author{
Nina Danilina* and Alireza Majorzadehzahiri \\ Moscow State University of Civil Engineering, Yaroslavskoe shosse, 26, Moscow, 129337, Russia
}

\begin{abstract}
The present research has sought to identify the features and capabilities of the smart city and their status in Tehran, identifying the strengths and weaknesses of this city in comparison with the smart city. For this purpose, first, the models and foundations of the smart city and its features presented by other researchers have been studied. The result of this study was to categorize Smart City features into six categories. The field survey of the topic by descriptive-survey method showed that these characteristics are confirmed by the statistical community as the characteristics of the smart city. With the ranking of 50 effective features, in addition to identifying important features in each category, 10 characteristics were identified as the most effective characteristics. The results show that among 50 characteristics, Tehran has only a relatively good status in eight characteristics. In other words, $84 \%$ of the characteristics in Tehran are not well-suited. The existence of such a situation cannot be ruled out by the integrated management factors on the affairs of the city of Tehran; there is no long-term plan for Tehran, and the relationship between people and government and the authorities is not related to partnership and cooperation.
\end{abstract}

\section{Introduction}

In the cities all over the world is a very disturbing trend in urban planning facing a problem of the future of the planet. The prognosis is that more than 5 billion people by 2025 will life in the cities, what occupies more than 75 percent of the world's population. This enormous urbanization process eve now causes a lot of socioeconomic problems, especially in developing countries. The way how to reduce the negative effect is sustainable urban development, as an essential component of the long-term vision of the community human being. Sustainable development, in fact, involves the process of socioeconomic, physical and environmental quality that guides members of local communities to the production and to the rebuilding of a purposeful life for the realization of sustainability dimensions. From that point of view, urban planning strategy should be aimed on achieving sustainable development and promoting the quality of the urban environment by balancing the spatial distribution of land use through "sustainable city form" [1-5]. At the end of the 20th century, inspired by the scientific foundations of sustainable development, a new approach

\footnotetext{
*Corresponding author: nina_danilina@mail.ru
} 
called "urbanization" and "smart growth" has been considered to sustain the spatial form of cities. In the era of globalization, the orientation of urban planning patterns in line with the optimal and sustainable land use mainly relies on the theoretical foundations of the conception of "smart city". World urban planning experience considers the smart city to be a process for static results in which increased employment of citizens, vital infrastructure, social capital and digital technologies will make a city more liveable and better responsiveness to challenges. A smart city means the integration and effective unification of physical, digital and human systems in the environment built to achieve the citizens' sustainable and prosperous future. A smart city is a city with all its vital infrastructure including roads, bridges, tunnels, railroads, subways, airports, docks, communications, water, power, and even main buildings to optimize resources consumption and provide comfort ability and security of people`s life. In general, we can say that the concept of a smart city is comprehensive and incorporates different domains, and can rely on this complexity, pillars, and characteristics to advance the path to urban development towards sustainability [6-9].

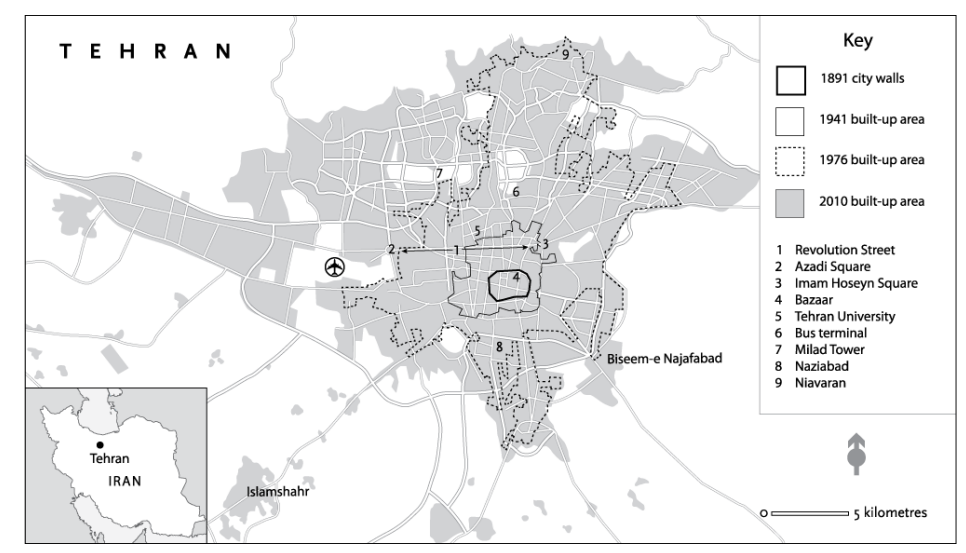

Fig. 1. Tehran city map

This article is devoted to the Tehran city as a metropolis with many problems. The population of Tehran is over 10 million people and its area is only 6 million, and because of this, the construction projects and services, however much done, alone will not meet the needs of the city of Tehran with this high population density. The intelligence of Tehran is particularly important because it is multiplying its population capacity. Recent studies also indicate that Tehran is ranked 28 in the poorest cities of the world in terms of quality of life. Considering the potential of the concept of the smart city, Tehran's metropolis can be upgraded in the domestic and international arena, placing it among cities that are moving towards sustainability (figure 1).

Considering the stated issues and the location of Tehran, the capabilities and requirements of creating the smart city of Tehran and more precisely the intelligence of Tehran should be investigated. Therefore, in this research, it is possible to answer questions such as whether Tehran has the potential for becoming a smart city and what are its requirements and infrastructure [10-12]. 


\section{Research method and data}

This research sought to answer two questions:

1. What are the general and specific characteristics and requirements of intelligent city?

2. What are the strengths and weaknesses of Tehran to become a smart city?

The aim was to do the descriptive - analytic research of main challenges of smart city and then to apply this analytic method for Tegran city. The first step was to identify the characteristics of Smart Cities. Then we collect initial data for research and the data collecting tool was a researcher-made questionnaire to scale ranking position of every character feature. Finally, for analyzing the data obtained from questionnaires completed by the sample population one-sample t-test, Friedman test, and test Kolmogorov - Smirnov have been used.

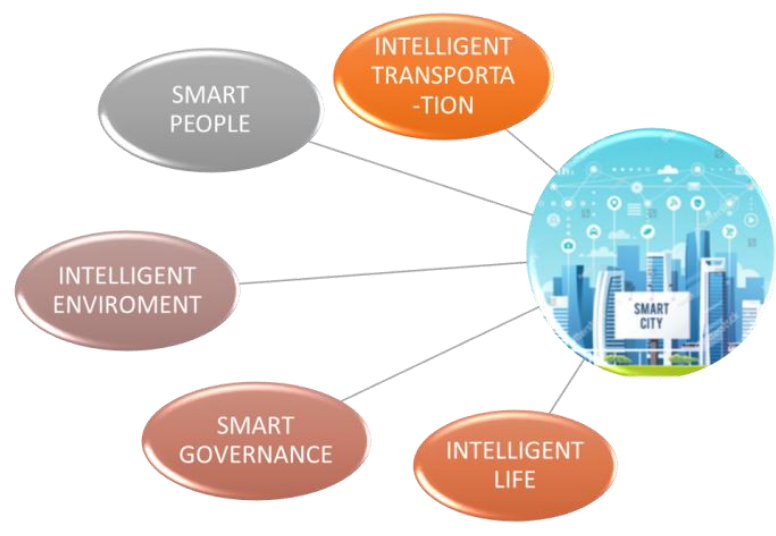

Fig. 2. Smart City model

In this research, Smart City characteristics have been evaluated on five variables of the smart economy, smart people, intelligent transportation, intelligent living, and intelligent governance (figure 2).

In response to the first question, according to the findings of the review, it was observed that researchers have presented numerous features for a Smart City model that were divided on six classes of features:

- Smart economy - 18 properties;

- Smart people -5 properties;

- Intelligent transportation -7 features;

- Intelligent life -5 properties;

- Smart Governance - 5 properties;

- Intelligent environment - 10 properties.

Taken together, these characteristics in this study led to the identification of the 50 features. In addition to the identification and characterization of Smart City, the next ranking is based on the importance of these features in a smart city. The respondents for the rating were specialists in the field of urban planning, management and urban environment technologies.

\section{Implementation}

This model and the results of the ranking were the base to the response to the second question and the study shows that $84 \%$ specificity in Tehran is not in good condition of smart city. Among 50 features were underlined main priorities for the extraction, using the 
results of the fourth quarter, based on a rule of thumb such as the Pareto principle - $20 \%$ Features considers as the most important factor. We underline 10 characters as the most important feature of the respondents considered.

In table 1 there are the detailed analysis of the current situation in Tegran on the basis of this rating is shown.

The results of the ranking can be seen:

1. "The application of information and communication technology infrastructure", "infrastructure The Broadband appropriate" and "favourable environment for economic growth" ranked first and third respectively in the smart economy.

2. In the intelligence community, the three characteristics of "creativity and innovation", "high level of education for citizens" and "people's participation in the affairs of the city" are more important.

Table 1. 10 Characteristics of Smart City in Tehran

\begin{tabular}{|c|c|c|c|c|}
\hline Rating & Feature & Component & Point & Situation \\
\hline 1 & $\begin{array}{l}\text { Intelligent Water Resources } \\
\text { Management }\end{array}$ & $\begin{array}{l}\text { Smart } \\
\text { environment }\end{array}$ & 31.99 & $\begin{array}{l}\text { it's } \\
\text { inappropriate }\end{array}$ \\
\hline 2 & Prospects in resource management & $\begin{array}{l}\text { Smart } \\
\text { environment }\end{array}$ & 31.62 & $\begin{array}{l}\text { it's } \\
\text { inappropriate }\end{array}$ \\
\hline 3 & Efficient transportation & Smart shipping & 31.24 & $\begin{array}{l}\text { Not very } \\
\text { desirable }\end{array}$ \\
\hline 4 & Citizens' access to health services & Smart governance & 31.17 & Fairly suitable \\
\hline 5 & $\begin{array}{l}\text { Physical infrastructure (road The, Rail } \\
\text { lines,..) }\end{array}$ & Smart shipping & 30.98 & $\begin{array}{l}\text { it's } \\
\text { inappropriate }\end{array}$ \\
\hline 6 & $\begin{array}{l}\text { Easy access to public and local } \\
\text { transportation }\end{array}$ & Smart shipping & 29.3 & Fairly suitable \\
\hline 7 & $\begin{array}{l}\text { Application of information and } \\
\text { communication technology } \\
\text { infrastructure }\end{array}$ & Smart economy & 29.16 & Fairly suitable \\
\hline 8 & $\begin{array}{l}\text { The integrity of the infrastructure of the } \\
\text { city }\end{array}$ & $\begin{array}{l}\text { Smart } \\
\text { environment }\end{array}$ & 28.84 & $\begin{array}{l}\text { it's } \\
\text { inappropriate }\end{array}$ \\
\hline 9 & Intelligent Energy Management & $\begin{array}{l}\text { Smart } \\
\text { environment }\end{array}$ & 28.55 & $\begin{array}{l}\text { it's } \\
\text { inappropriate }\end{array}$ \\
\hline 10 & Foundation The Appropriate bandwidth & Smart economy & 28 & $\begin{array}{l}\text { Not very } \\
\text { desirable }\end{array}$ \\
\hline
\end{tabular}

3. "The system The Efficient transportation", "physical infrastructure (road The What, railways, etc.)" and "easy access to public transportation and local" are a more important component of intelligent transportation.

4. Intelligent Life component features "access Citizens To Services Health And Health", "Housing Suitable And Level access To That To entire Citizens" and "charm Tourist Location Life" is of paramount importance.

5. Intelligent governance component features "integrated urban management and coordination of institutions", "inclusive e-government" and "the cooperation and participation of the people in urban affairs" are more important.

6. Smart media component features a "management Smart Sources Water", "future the door Management Sources" and "Integrated" Infrastructure Urban" are more important.

7. Excluding three properties "citizens' access to health services", "Easy access to public transportation and local" and "Application infrastructure The Information and Communication Technology", which has a relatively good status, the status of the other seven characteristics are inappropriate.

Another analysis of all collected data allows us to form the list of strengths and weaknesses of Tehran city according to the Smart city model. The strengths and 
weaknesses of Tehran in connection with the features of a Smart City are shown in the table 2.

The results showed that in Tehran resources and management challenges face serious to critical water and energy resources. To appear to be due to the lack of a comprehensive long-term plan as a result of short-term oriented program planners and decision-makers is a senior.

In terms of infrastructure, physical as well as the city's usual practice is not desirable. Such a situation can be traced to several factors:

Table 2. The list of strengths and weaknesses of Tehran city

\begin{tabular}{|c|c|c|}
\hline Row & Feature & Current status \\
\hline \multicolumn{3}{|c|}{ Strengths of Tehran } \\
\hline 1 & Application infrastructure of information and communication technol. & Fairly suitable \\
\hline 2 & A favorable environment for economic growth & Fairly suitable \\
\hline 3 & Dynamic economy & Fairly suitable \\
\hline 4 & The ability to make decisions the production of services and products & Fairly suitable \\
\hline 5 & Easy access to public and local transportation & Suitable \\
\hline 6 & Use different modes of transportation & Suitable \\
\hline 7 & Citizens' Access To Health services Health & Fairly suitable \\
\hline 8 & The attractiveness of Tourist Location Life & Fairly suitable \\
\hline \multicolumn{3}{|c|}{ Tehran's weaknesses } \\
\hline 1 & Foundation The Appropriate bandwidth & Fairly inapprop. \\
\hline 2 & Integration of Services and Infrastructure The S & Inappropriate \\
\hline 3 & Industry and university relationship & Inappropriate \\
\hline 4 & H environment protection & Inappropriate \\
\hline 5 & High energy efficiency in industries & Inappropriate \\
\hline 6 & Use energy The Renewable industries & Inappropriate \\
\hline 7 & Knowledge-based economy & Inappropriate \\
\hline 8 & Capacity to attract capital & Fairly suitable \\
\hline 9 & To meet the challenges of economic & Inappropriate \\
\hline 10 & Promotion and encouragement for entrepreneurship & Inappropriate \\
\hline 11 & Non-false employment generation & Inappropriate \\
\hline 12 & Economic stability based on net production & Inappropriate \\
\hline 13 & Use available resources to provide a solution The New Ones & Inappropriate \\
\hline 14 & Ability to charge tax on public services & Fairly inapprop. \\
\hline 15 & Model The New financial and capital & Inappropriate \\
\hline 16 & creativity and innovation & Fairly inapprop. \\
\hline 17 & High level of education for citizens & Fairly inapprop. \\
\hline 18 & Public Participation in City Affairs & Inappropriate \\
\hline 19 & People Activities ICT Platform & Fairly inapprop. \\
\hline 20 & system Efficient transportation & Fairly inapp. \\
\hline 21 & Physical infrastructure (road The, Rail lines, and...) & Inappropriate \\
\hline 22 & The efficient movement of people, goods and vehicles & Inappropriate \\
\hline 23 & System The Intelligent Transportation & Inappropriate \\
\hline 24 & Supporting the Information and Communication & Inappropriate \\
\hline 25 & Housing Suitable And Level access To ThatTo entire Citizens & Inappropriate \\
\hline 26 & Provision of services Varied social ToCitizens & Inappropriate \\
\hline 27 & Manage e-health & Inappropriate \\
\hline 28 & Integrated Urban Management and Coordination of Institutions & Inappropriate \\
\hline 29 & e-Government capability & Fairly inapprop. \\
\hline 30 & The level of cooperation and presence of people in urban affairs & Inappropriate \\
\hline 31 & The amount of citizens' participation & Inappropriate \\
\hline 32 & Citizens' access to information and data related to city management & Inappropriate \\
\hline 33 & Intelligent Water Resources Management & Inappropriate \\
\hline 34 & Future vision the door Resource management & Inappropriate \\
\hline
\end{tabular}




\begin{tabular}{|l|l|l|}
\hline 35 & Integrated infrastructure Urban & Inappropriate \\
\hline 36 & Intelligent Energy Management & Inappropriate \\
\hline 37 & Use Information Technology And Resource management & Inappropriate \\
\hline 38 & Use From Power of appeals allowed Andrew & Inappropriate \\
\hline 39 & Intelligent waste management & Inappropriate \\
\hline 40 & Building Of Smart, stable And Compatible With Environment & Inappropriate \\
\hline 41 & Program planning proper use of land And Mixing use of & Inappropriate \\
\hline 42 & Passive defence & Inappropriate \\
\hline
\end{tabular}

1. integrated management of the affairs of Tehran, not ruling. The centers of policy and decision-making are several in the city of Tehran decides to take. In fact, there is no single leader for the management of the city of Tehran.

2. There is no long-term plan for Tehran. Thus, each institution based on their interests and policy objectives and actions and big thinking and big interests in Tehran and people in decision-making of it and not see it. Most bias and political influence.

3. The relationship between people and governance and the authorities is not the relation of partnership and cooperation. Simply put, people in Tehran in decision-making related to the city cooperate with authorities and stakeholders do not.

\section{Conclusions}

The suggestions presented below regarding the situation in Tehran are the problems and problems facing it and based on the results of the questionnaire. So suggestions are made for the six smart city components.

- Smart economy

1. Presentation of a new financial model based on the potential and capacities of Tehran and the creation of sustainable income, for example, support of new institutions and knowledge base

2. Attracting investment from international research and technology institutes to lead Tehran to a technology ecosystem

3. Creating competition among investors to invest more in the smart city market and ICT

4. Use of new energies considering the potential of Tehran to meet its needs

- $\quad$ Smart people

1. Promoting Citizen's Education on Smart City and Information Technology

2. Strengthen the creativity and innovation of citizens and support their ideas on urban issues

- Dynamic (Intelligent Transportation)

1- Using Intelligent Transport Systems with Information and Communication Technology Support

2- Make some minor changes to the transport structure for pedestrian and public transport

2- Emphasis on public transport and pedestrian traffic and the pioneering urban authorities

3- Considering special facilities for new and non-polluting energy vehicles

- Smart governance

1. Establishing an institution or organization with the participation of all stakeholders as the smart city that is responsible for this

2. The creation of a research institution, future-oriented (center Yndpzhvhy) as well as decision-makers and urban management Tehran

3. Development of Information Technology Infrastructure

4. Public participation, especially in the neighborhood scale

5. Starting projects on a local scale as examples and, if successful, doing them on a city scale

- Smart life 
1. Culture and education to change people's behavior from consumer to producer and to support home-based businesses and small and medium-sized enterprises.

2. The evolution of the educational system based on the present and future manpower capabilities based on operational training

- Intelligent environment

1. Modification of Tehran's urban landscape system by modifying laws and policies, for example, Twin Construction Criteria based on green buildings and climate-friendly

2. Intelligent management of resources, especially water resources, using information and communication technology

3. Utilize the potential of municipal waste and wastewater for energy production

According to the results of this study, it can be concluded that Ali is one of the weaknesses in the city of Tehran that has the ability to create a smart city by applying changes to structures, especially in the field of management. This will only be possible by integrating urban management and infrastructure and the participation of all stakeholders. In the end, it is necessary to explain that by reviewing the literature of this research it can be deduced that many of the cases that the smart city attempts to achieve are expressed in the landmine document.

This work was financially supported by Ministry of Science and Higher Education of the Russian Federation (\#NSh-3492.2018.8).

\section{References}

1. Pour A, Sarascanrood A A, etc. Journal of Research in Human Geography 69 50-29.

2. Candia, A, Represa S N, Giuliani, D, Luengo M ASolutions for SmartCities: Proposal of a monitoring system of air quality based on a LoRaWAN network with low-cost sensors Tavakolinia J, Mansour S Human geography 70 pp . 43-29.

3. Sheina, S, Fedorovskaya, A, Yudina, K "Smart City": Comfortable Living Environment IOP Conference Series: Materials Science and Engineering v. 463, is. 3, 032095

4. Gadecki, J. Smart Cities: Challenges for the Community TechSpo 2018 (Krakow, Poland), 8584183

5. CACIDI 2018 (Buenos Aires; Argentina) CFP18H47-ART, 143796

6. Lotfi M, Yousefi A, Jafari S The effect of emerging green market on green entrepreneurship and sustainable development in knowledge-based companies Sustainability v.10, is. 7, 2308

7. Fotouhi S, Shirali-Shahreza H, Mohammadpour, A Concentration prediction of air pollutants in Tehran SCIOT 2018 (Mashhad; Iran), 143211

8. Korolev A Smart city: theory and practice of creating intelligent cities Int. Jour.of Open Information Technologies 2018 v. 6 No.11 pp. 54-58.

9. Hashemi S Z, Mirahmadi S M Urban services providers in Tehran municipality region Jour. of Advanced Research in Dynamical and Control Systems 2018, 10, Is. 7 pp 31-41

10. Schirrer M The smart city against the city. urban coup by the economic producers of the smart city Practical Geography and XXI Century Challenges International Geographical Union Thematic Conference dedicated to the Centennial of the Institute of Geography of the Russian Academy of Sciences 2018 pp. 717-718.

11. Motieyan H, Mesgari M S Towards sustainable urban planning through transitoriented development (A case study: Tehran) Int. Jour. of Geo-Information 6, is. 12, 402

12. Sherbina E.V.E., Danilina N.V.E., Vlasov D.N. City planning issues for sustainable development Int. Jour. of App. Eng. Res. 201510 22, 43131-43138. 